\title{
Spatial variability of biogenic elements and organic carbon content in the tributaries of Lake Baikal
}

\author{
Ekaterina Sharapova*, Ludmila Efimova, Irina Denisova, Aida Ermekova, Mikhail \\ Lychagin, and Sergey Chalov \\ Lomonosov Moscow State University, Faculty of Geography, 1 Leninskiye Gory, 119991, Moscow, \\ Russia
}

\begin{abstract}
The article considers the features of biogenic elements and organic carbon (Corg) content spatial variability in the Lake Baikal tributaries. The role of hydrological conditions and landscape-geochemical features in the chemical elements flow formation is shown. It was found that organic carbon in the river waters is represented mainly by its dissolved form. In the lower reaches of the Selenga, erosion processes and economic activity in the catchment area increase the proportion of suspended forms of organic carbon and mineral phosphorus. In the river delta under the influence of the sedimentation and the intake of organic matter formed during aquatic vegetation decomposition, the content of dissolved Corg increases with a contemporary decrease in its suspended form. As a result of intensification of production and destruction processes in well-heated areas of the delta, a significant decrease in the concentrations of mineral phosphorus and an increase in organic phosphorus occur.
\end{abstract}

\section{Introduction}

Baikal is a unique natural reservoir classified as a UNESCO World Heritage Site which contains about $20 \%$ of all fresh water reserves in the world. In the modern period, local transformations of lake's littoral system take place in its shallow areas, there is an active eutrophication process, the formation of areas with the massive development of filamentous algae, previously not characteristic of lake waters, takes place. Local contamination of the Baikal coast zone is attributed to increased recreational load and diffusion runoff. Baikal tributaries play a crucial role in the chemical composition formation of water in coastal parts of the lake, which may contain human-made pollutants, in particular biogenic and organic substances entering rivers together with household and industrial runoff. The reason for the deterioration of water quality in the tributaries of the lake and its littoral zone is not only economic activity in the catchment area, tourism and recreation, but also the decrease in water quality due to climatic changes in the territory of the Baikal region.

\footnotetext{
*Corresponding author: koshakosha97@gmail.com
} 
The purpose of this study is to identify the spatial characteristics of biogenic and organic substances distribution in the mouth regions of the main tributaries of Baikal and to consider their impact on the water quality in the lake.

\section{Materials and methods}

The study is based on data obtained during field works carried out from July 27 to August 10, 2018, as well as from July 25 to August 11, 2019 by students and employees of the Moscow State University Faculty of Geography as part of Baikal expedition of the Russian Geographical Society. The selection of test points within each river took into account the change of natural conditions of the Baikal basin - relief, geological structure of the territory, soil cover, vegetation. River testing took place in the lower reaches of the rivers. Apart from the main tributaries of the lake, attention was paid to medium and small aqua landscapes, as the most sensitive to changing conditions. Estuarine areas were chosen because they are the final accumulators of the substances brought in.

During both surveys (2018 and 2019), 55 and 52 water samples, respectively, were taken from the tributaries of the northern, southern and eastern parts of the Baikal watershed (Fig.1).

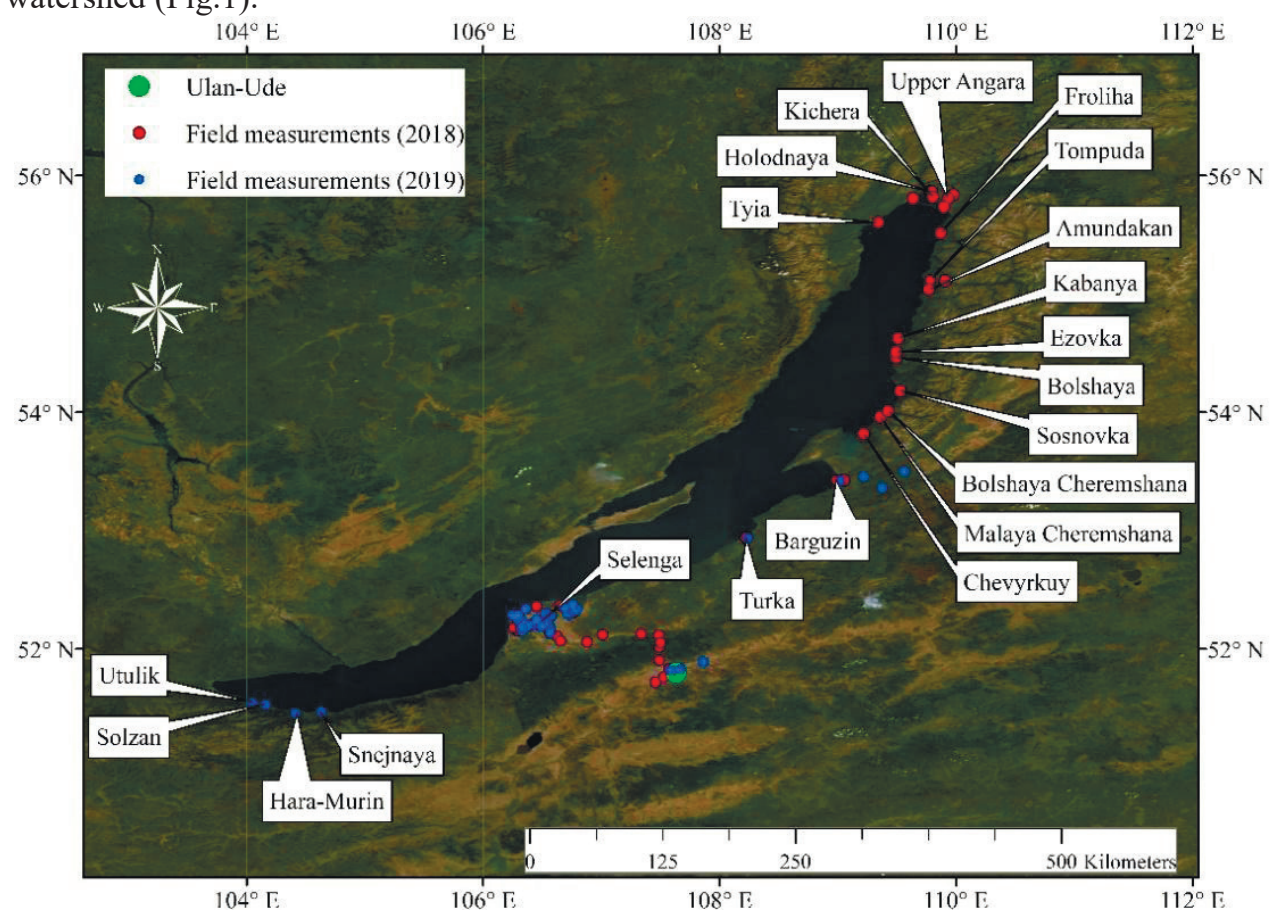

Fig. 1. Field measurements and sampling points.

The biogenic cell samples were filtered through a membrane filter with a pore diameter of $0.45 \mathrm{~mm}$ and frozen. The samples were analyzed in the hydrochemical laboratory of the Krasnovidovo Educational and Scientific Station of the Moscow State University. The content of orthophosphates and total phosphorus in filtered and unfiltered samples was determined by Morphi-Riley according to [1]. The mineral silicon content was determined by photometric method as yellow silicomolibdene heteropolyacid [2]. The content of total nitrogen was determined by spectrophotometric method in the ultraviolet range after persulfate oxidation in alkaline condition [3]. The content of nitrates and ammonium ions was determined by ion chromatography [2]. 
Samples were filtered to determine dissolved organic carbon through pre-prepared fiberglass filters. Organic carbon content was carried out in the laboratory of the Soil Faculty of Moscow State University. The dissolved carbon was detected on a liqui TOC analyzer from ELEMENTAR Analysen systeme by high temperature oxidation. The suspended form of organic carbon was determined on a CHNS elemental analyzer from Elementar.

\section{Results and discussion}

In the waters of the Lake Baikal tributaries, the content of biogenic and organic substances varies markedly and depends on the natural conditions of the basins and the level of anthropogenic load on the watershed. The hydrometeorological situation plays a crucial role in the flow, transport and transfer of biogenic and organic substances to Baikal. The main share in the flow of biogenic and organic substances into the lake is in the 3 largest rivers - Selenga, Barguzin and Upper Angara.

Both 2018 and 2019 expeditions took place during summer floods. Thus, in 2018 on Selenga river a powerful rain flood was observed, water discharge increased from almost $900 \mathrm{~m}^{3} / \mathrm{s}$ to more than $2000 \mathrm{~m}^{3} / \mathrm{s}$. Transporting capacity of the river also increased to $20,000 \mathrm{~kg} / \mathrm{m}^{3}$. During the study period, turbidity values in the Selenga river were also high, with values ranging from 60 to $200 \mathrm{mg} / \mathrm{l}$. A similar hydrometeorological situation was observed during the expedition in 2019.

The basin differences in silicon concentrations in the tributaries are due to the composition of rocks and catchment soils, the depth of entry of the mounds and the hydrological situation determining the ratio of the shares of underground and surface waters in the rivers feed.

During the survey period, the concentration of silicon in the waters of the tributaries surveyed varied from 2.5 to $8 \mathrm{mg} / \mathrm{l}$. Comparative analysis of these expeditions showed slight differences in dissolved silicon content. The minimum silicon content (2.5-3.6 mg/l) is typical for the southern coast of Lake Baikal, originating on the Hamar Daban Ridge. These rivers have very little mineralization (less than $50 \mathrm{mg} / \mathrm{l}$ ), with little groundwater role in their nutrition. The silicon content in the waters of the Upper Angara and Barguzin rivers is 3-4 mg/l. The rivers have a mountainous catchment, thus, with the observed increase in temperature in the Baikal basin, the proportion of low-mineralized melt waters with low silicon content increases.

In the lower Selenga River, the concentration of $\mathrm{Si}$ is $1.5-2.5$ times higher than in other rivers and is $6-7 \mathrm{mg} / \mathrm{l}$, which corresponds to the average summer content of the element. The waters of the Selenga River bring more than $50 \%$ of its total silicon entry into the lake. Silicon is the most important element in Baikal aquatic ecosystem. As in many freshwater bodies, its entry into the lake along with river flow determines the development of diatomic algae, the main producer of organic matter. In the Selenga Basin, a period of reduced water content has continued since 1996 [4], which has led to an increase in the share of groundwater in the rivers feed and an increase in silicon concentrations in its waters.

At the beginning of the 21 century the decrease of silicon content in the trophogenic layer of lake water [5] was revealed, which continues at the present time. Despite the increase in silicon in Selenga water due to the low reduction of the total silicon discharge to Baikal compared to the average summer values [6].

According to monitoring studies conducted by the Baikal Institute of Nature Management of the Russian Academy of Sciences, under the influence of anthropogenic factor in the main tributaries of Lake Baikal (especially in the Selenga River below UlanUde), concentrations of ammonium and nitrite nitrogen are gradually increasing, which leads to a restructuring of the ratios between forms of mineral nitrogen entering Baikal. 
Along with silicon, nitrates and mineral phosphorus (orthophosphates) are essential components needed to form primary products in a water reservoir. The multi-year trend of nitrate content on Baikal littoral tends to decrease, for mineral phosphorus there is also a decrease while increasing its organic form [7]. The results of the 2018 and 2019 expeditionary studies confirm this trend, but it is broken by hydrometeorological conditions.

Concentrations of total and mineral phosphorus vary in Baikal tributaries in the broad range of 11 to $180 \mathrm{mcg} / \mathrm{l}$ and 10 to $147 \mathrm{mcg} / \mathrm{l}$, respectively. The relationship between phosphorus forms shows that the organic form of the element prevails in the water of most of the rivers. The minimum phosphorus content is noted in the Tompuda river. Low phosphorus values dominated by its dissolved mineral form were observed in rivers flowing from the Hamar-Daban Range. Small tributaries of the eastern part of the Baikal basin are characterized by high hydrodynamic activity and low water turbidity values.

The predominance of mineral total phosphorus over organic phosphorus was observed and in the Selenga River above delta (Pmin/Porg ratio reached 3). This could be probably caused by occurrence of the extreme flood during the field works, and, as a result, by the additional supplement of Pmin during its flush from the watershed. The increase in turbidity of water during the period of increased runoff is caused by the arrival of suspended particles from the watershed due to the low resistance of soils and rocks to erosion, as well as, affected by agricultural factor through which the increase in turbidity is evident in the areas of ploughing and livestock grazing. The concentration of suspended mineral phosphorus was thus well related to the turbidity of the water.

In the Selenga Delta watercourses, the concentration of total phosphorus is much higher than in the water of other lake's tributaries and vary over a wide range (48 to $188 \mathrm{mcg} / \mathrm{l}$ for Ptotal). Organic phosphorus prevailed over mineral phosphorus. During the summer period, when phytoplankton in the delta grows significantly, mineral phosphorus can be almost completely consumed by organisms. The proportion of organic phosphorus, thus, increases to $60 \%$ or more. At the same time due to inclusion of plankton organisms in bodies more than half of phosphorus is in suspended form. The maximum concentrations of total and organic phosphorus are observed in shallow water areas of the delta, where production processes are active. Here a decrease in the flow rate up to $0.5 \mathrm{~m} / \mathrm{s}$ was observed - up to 0.5 $\mathrm{m} / \mathrm{s}$ compared to the velocities of $1-2 \mathrm{~m} / \mathrm{s}$ in other rivers, besides, these areas are characterized by the maximum content of chlorophyll "a" - up to 10-14 mcg/l (while its concentration in other studied rivers does not exceed $3 \mathrm{mcg} / \mathrm{l}$ ). Processes of substances sorption on suspensions and depositions to the bottom prevail over transformation processes.

The ratio of mineral and organic forms of nitrogen $(\mathrm{Nmin} / \mathrm{Norg})$ in the waters of almost all the surveyed tributaries of Baikal is less than one, therefore it can be concluded that in the water bodies under consideration there are production processes, however, their intensity in different rivers varies (the maximum value in the Selenga river is 0.9).

Corg is a critical measure in the total organic matter (OM) estimation. Organic carbon concentration is assumed as $50 \%$ of the whole OM content. Similarly, the total phosphorus content varies in the Baikal tributaries of dissolved organic carbon, which in the surveyed waters is predominantly in dissolved form (on average $76 \%$, ranges from 69 to $99 \%$ ). The average concentration of Corg in water for all the tributary rivers considered is $6.2 \mathrm{mg} / \mathrm{l}$. The average content of Corg is the Selenga River $-8.3 \mathrm{mg} / \mathrm{l}$ (Fig. 2). The maximum Corg content (up to $14 \mathrm{mg} / \mathrm{l}$ ) is observed in parts of the delta where production processes are active. This is most likely cost by good warming of the river waters, which stimulates the rapid development of aquatic vegetation and decomposition of accumulated biomass, as well as soils - alluvial soddy soils and humus-rich soddy soils, which are the sources of dissolved organic carbon. 
In the lower reaches of the river, dissolved organic carbon increases by $20 \%$. On the watershed of the river an organic matter enrichment occurs due to active ploughing of agricultural land located in the river floodplain and related flat erosion, as well as under the influence of the city of Ulan-Ude - the average concentration of organic matter in the waters of the treatment facilities of Ulan-Ude thermal power plant-1 - can reach $31 \mathrm{mg} / 1$ [8]. In the lower Selenga and its delta, the ratio of dissolved organic carbon to suspended carbon is $71 \%$ to $29 \%$.

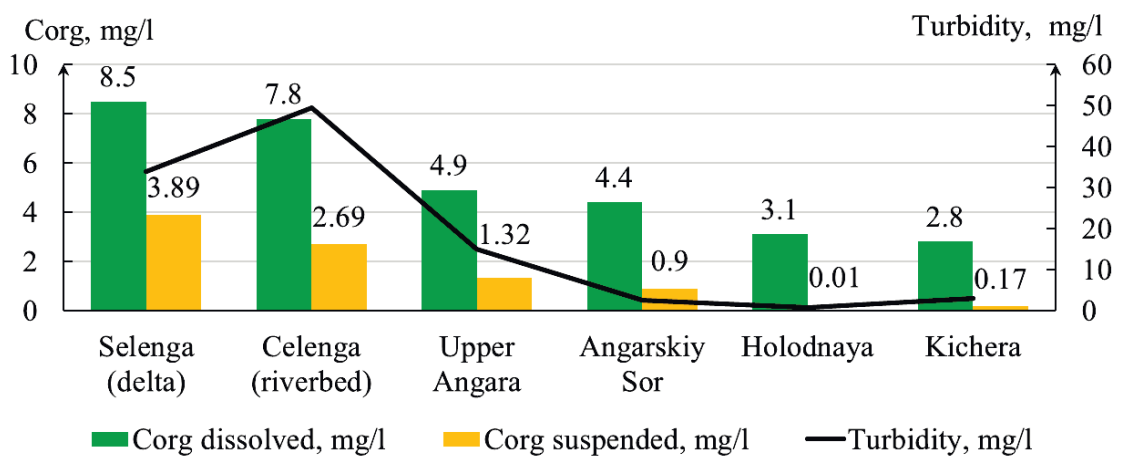

Fig. 2. Turbidity, dissolved and suspended organic carbon in the Lake Baikal tributaries.

Majority of the Lake Baikal eastern coast tributaries lie in the mountainous area meaning high velocities regime. During summer flash floods there is an increase in discharges, but the content of suspended Corg remains small due to the lack of aquatic vegetation, and the poverty of the soil with humus (entic podzols and albic podzols), the turbidity of the waters is small. The dissolved organic carbon content is equal to $2 \mathrm{mg} / \mathrm{l}$, the suspended organic carbon content differs from 0.01 to $0.03 \mathrm{mg} / \mathrm{l}$, and the dissolved form exceeds the suspended one by 40 times.

The diversity of geomorphological, soil and landscape-geochemical conditions of the catchments of Lake Baikal tributaries, together with the influence of the physical and chemical properties of the elements, creates ambiguous dependencies between their content and the factors of formation of the surface waters chemical composition. Conditions of chemical element migration in landscapes outside river valleys are determined by relief conditions combined with properties of rocks and soils. For the mountain relief, the processes of denudation, carry-out and transit of the chemical elements in question are predominant. Narrow valleys of small tributaries with undeveloped floodplain play a role of transit zones [9]. Leaching of chemical elements and enrichment of surface waters does not occur due to short-term contact between water and rocks. The lowland areas are characterized by a transit-accumulative type of landscape (lower current and Selenga delta) and an accumulative type of landscape (Ezovka and Turka rivers). During drainage of lithosols, entic podzols and albic podzols formed on well-washed crystalline rocks of mountain and lowland areas of the taiga zone (Tyia, Snejnaya, small Hamar-Daban River) waters with very low mineralization and reduced $\mathrm{pH}$ values are formed. In the water of these tributaries, concentrations of biogenic elements and organic carbon are extremely low. High positive correlation coefficients are found between the mineral nitrogen content and the soils of peatlands and gleysols, which are present on the catchments of marshland rivers (Ezovka). Mineral and total phosphorus correlates with iron because it forms compounds with it. 


\section{Conclusions}

An analysis on the spatial distribution of nutrients and organic carbon in the waters of Lake Baikal tributaries revealed the dependence of their content on the geological and landscape conditions of the catchments. Low concentrations and dominance of the dissolved form of nutrients and organic substances in the waters of small tributaries of the lake are caused by high flow rates and reduced water temperatures, leading to oligotrophic conditions and poor development of aquatic vegetation. The soil cover in the basins of small tributaries is represented by entic podzols, albic podzolsand lithosols with a low organic content. The variety of geomorphological and landscape-geochemical conditions of the Lake Baikal large tributaries catchments, as well as the influence of the anthropogenic factor, creates ambiguous relationships between the content and form of biogenic and organic substances and the factors of their formation.

It was found that in the waters of the Lake Baikal tributaries, organic carbon is mostly presented by dissolved form, which accounts for an average of $84 \%$, from $71 \%$ in the Selenga delta to $99.7 \%$ in the Holodnaya river, while the excess of the dissolved form of Corg over the suspended one reaches 40 times.

The hydrodynamic conditions of rivers play a significant role in shaping the transport structure of biogenic and organic substances. During the summer flood the proportion of finely dispersed fractions in the composition of suspended sediments increases, their flow is associated with surface natural and man-driven flushing. Small particles with high sorption ability change the transport structure of biogenic and organic substances, leading the proportion of suspended forms of organic carbon, mineral and total phosphorus to increase. In the river delta the hydrodynamic conditions change, causing the processes of suspension sedimentation and supplement of organic matter formed during the decomposition of aquatic vegetation to intensify. The dissolved Corg content increases, while its suspended form reduces.

As a result of production and destruction processes intensification in well-heated areas of the delta, a significant decrease in the concentrations of mineral phosphorus and an increase in organic phosphorus content occurs. The proportion of organic phosphorus entering the lake increases to $60-70 \%$. Moreover, due to consumption by planktonic organisms, more than half of the organic phosphorus is observed in suspended form.

This study was supported by Russian Foundation for Basic Research (project 17-29-05027_a; 17-0541174 - RGO a).

\section{References}

1. J. Murphy, J.P. Riley, Anal. Chim. Acta 27, 31-36 (1962).

2. L.M.L. Nollet, L.S.P. De Gelder, Handbook of Water Analysis (CRC Press, 2013).

3. Analytical, kinetic and calculation methods in hydrochemical practice/under ed. P. A. Losovik, N.A. Efmenko. SPb.: Nestor History, 272 (2017).

4. N.L. Frolova, P.A. Belyakov, V.Yu. Grigoriev, A.A. Sazonov, L. Zotov, Water Resources 44, № 3, 243-255 (2017).

5. M. N. Shimarayev, V. M. Domysheva, Geology and geophysics 3, 310-316 (2004);

6. L.M. Sorokovikova, I.V. Tomberg, V.N. Sinyukovich, V.G. Ivanov, International Conference "Freshwater Ecosystems - Modern Challenges.", 324- 325 (2018).

7. T.V. Hodger, V.M. Domysheva, L.M. Sorokovikova, L.P. Golobokova, M.V. Sakirko, I.V. Tomberg, O.G. Nezvetayeva, V.N. Sinyukovich, International Conference "Freshwater Ecosystems - Modern Challenges.", 55-56 (2018).

8. State Report "On the State and Protection of the Environment of the Russian Federation in 2014." M.: Ministry of Natural Resources and Environmental Protection of the Russian Federation; NPP Kadastr, 841 (2015).

9. Ecological-geographical atlas-monograph "Selenga-Baikal"/under ed. N.S. Kasimov. Moscow: Faculty of Geography of Moscow State University, 288 (2019). 